\title{
角柱のクロスフロー振動に対する後流平板の干渉効果*
}

\author{
川畑 佑介*1，高橋 勉*1，萩野谷 剛*2，白樫 正高*1
}

\section{Interference Effect of Downstream Strip Plate on the Crossflow Vibration}

\author{
of a Square Cylinder
}

\author{
Yusuke KAWABATA*1, Tsutomu TAKAHASHI, Takeshi HAGINOYA and Masataka SHIRAKASHI \\ ${ }^{* 1}$ Nagaoka University of Technology, Kamitomioka 1603-1, Nagaoka, Niigata, Japan.
}

Wind tunnel experiments are carried out to investigate interference effect of downstream strip plate of width $w=d$ on the crossflow vibration of a square cylinder with a side length $d=26 \mathrm{~mm}$. While sufficient suppression of Karman vortex induced vibration is not attained by plates with crossflow height less than $l_{d}=4 d$, the galloping is suppressed even by a square plate, i.e. $l_{d}=d$, when the gap ratio $1<s / d<2.0$. When a plate of $l_{d} \leqq 2 d$ is set with a gap ratio $s / d<1 \sim 1.4$, a large vibration occurs at $U>5 \mathrm{~m} / \mathrm{s}$ with the maximum amplitude at around $s / d=0.3$. The amplitude at $s / d=0.3$ increases divergently with flow velocity. Measurement of the lift force on the square cylinder and the velocity in the near wake for the corresponding fixed system shows no evidence for periodic change of flow responsible for the vibration. A prediction of this vibration based on the quasi-static hypothesis suggests that the vibration is caused by the fluid-elastic instability but not by a periodic vortex shedding. Hence, the name "Wake Body Interference Fluid Elastic Vibration (WBIFEV)" is proposed for this vibration.

Key Words : Flow Induced Vibration, Fluid Ellastic Vibration, Interference Effect, Cruciform Arrangement

\section{1. 緒 言}

一様流に対して crossflow 振動が可能なように弾性支持された柱状体は，流れによりカルマン渦励振(Karman Vortex Induced Vibration: KVIV)やギャロッピング等の振動を示すことが知られている.これらの振動の抑制方法に ついてはこれまでに多くの研究がなされており, 下流に柱状物体を振動物体に対してタンデム配置する方法や(1 5), 別の物体を直接取り付ける方法 ${ }^{(4,6)}$, 物体の上下に 2 次元翼型をある間隔で取り付ける方法( () などが提案されてい る. また, タンデム配置した柱状体の位置によっては元の振動よりも大きな振動が発生する ${ }^{(5)}$. これらの方法で は流れ場に 2 次元的な影響を与えることにより振動を制御する. これに対して, 柱状体の後流に別の柱状物体を 十字交差配置することで, 振動体に手を加えることなく 3 次元的な流れの干渉効果で振動が抑制される現象や新 たな振動状態が誘起される現象の発生が明らかとなってきた.

Bae $ら^{(7)}$ は, 直径 $d$ の円柱の下流に, 同径の円柱を隙間 $s$ で十字交差配置することにより KVIV が抑制されるこ とを見出した. また, KVIVよりも高い流速で交差部近傍から流出する縦渦(Longitudinal vortex)による振動(LVIV) が発生することを確認した，その後，この縦渦には隙間比 s/dに依存して，その形状と周波数が異なる Trailing Vortex(TV)と Necklace Vortex(NV)の 2 種が存在することが示された ${ }^{(8)}$. 小出ら ${ }^{(9)}$ は, 干渉効果がより大きいことが 期待される下流物体して, 幅 $w$ が $w / d=0.5 \sim 1.75$ の長い帯状の平板を円柱の下流に十字交差配置し, 円柱の振動 に対する影響を調べた，その結果，KVIV の抑制効果は円柱の場合よりも大きく, 円柱直径の半分の幅の平板に より，上流円柱と直径が等しい円柱とほぼ同様の抑制効果が得られること，および $w \leqq d$ の平板で $s / d$ のある範囲 でKVIV が増加することを報告した. また， LVIVについてはw/dによって 2 種の LVIV の発生する s/d の範囲が

\footnotetext{
* 原稿受付 2010 年 8 月 20 日

*1 正員, 長岡技術科学大学 (T940-2188 新潟県長岡市上富岡町 1603-1)

*2 日産自動車(株)（厂243-0192 神奈川県厚木市岡津古久 560-2）

E-mail: bata@stn.nagaokaut.ac.jp
} 
異なり, $w=d$ の平板では Trailing 渦による振動(TVIV)のみが発生することを明らかにした．Koide ら ${ }^{(10)}$ は一辺 $d$ の正方形柱(以後角柱と記す)の下流に, 幅 $w=0.5 d \sim d$ の十分に長い平板を十字交差配置し KVIV とギャロッピン グに対する影響を調べた，その結果，下流平板は KVIV とギャロッピングの両者に対して顕著な抑制効果を持つ とともに，円柱の場合と類似の KVIV が増大する現象が発生することを見出した．また，隙間比 $s / d=1.4$ 付近 で 縦渦による渦励振が発生する現象を見出し, これが Trailing 渦によるものである可能性を指摘した. 筆者ら ${ }^{(11)}$ 前報で寸法の異なる相似な系について同じ現象が起こることを確認し，さらに，平板幅 $w の$ 影響を調べた．その 結果, 系の大きさによらずギャロッピングは抑制され, その効果は w/d が大きいほどより大きな隙間比 $s / d$ で得 られることを示した。 また角柱表面の流れの観察から上述の縦渦励振が Trailing 渦によるものであることを示し た.

\section{主要記号一覧}

$C_{D}$

$C_{L}$

$C_{z}$

$d$

$F_{D}$

$F_{L}$

$F_{Z}$

$f_{n}$

$f_{L}$

$f_{u}$

$f_{v}$

$f_{v 0}$

$f_{z}$

$l_{d}$

$S_{C}$

$S_{L}$

St

$S_{u}$

$S$

$U$

$U^{*}$

u

W

$w_{C}$

$w_{F z}$

Z

$\alpha$

$\delta$

添え字等

0

$\infty$
抗力係数, $=F_{D} /\left(1 / 2 \rho U^{2} d L\right)$

揚力係数, $=F_{L} /\left(1 / 2 \rho U^{2} d L\right)$

$Z$ 方向の流体力係数, $=F_{Z} /\left(1 / 2 \rho U^{2} d L\right)$

角柱の 1 辺の長さ [mm]

抗力 $[\mathrm{N}]$

揚力 $[\mathrm{N}]$

$\mathrm{Z}$ 方向の流体力 $[\mathrm{N}]$

系の固有振動数 $[\mathrm{Hz}]$

変動揚力のスペクトル $S_{u}$ のピーク周波数 $[\mathrm{Hz}]$

角柱後流の速度変動 $u$ のスペクトル $S_{u}$ のピーク周波数 $[\mathrm{Hz}]$

洞流出周波数 $[\mathrm{Hz}]$

固定系での渦流出周波数 $[\mathrm{Hz}]$

角柱の振動数 $[\mathrm{Hz}]$

下流平板の有効長さ $[\mathrm{mm}]$

スクルートン数, $=2 m_{e} \delta / \rho d^{2} L$ ( $m_{e}$ : 有効質量 $)$

変動揚力のリニアスペクトル

ストローハル数, $=f_{v} d / U$

物体後流における $\mathrm{x}$ 方向の速度変動 $u$ のリニアスペクトル

角柱と下流平板の間隔 $[\mathrm{mm}]$

主流速度 $[\mathrm{m} / \mathrm{s}]$

無次元流速, $=U / f_{n} d$

角柱後流の速度変動 $[\mathrm{m} / \mathrm{s}]$

下流平板幅 $[\mathrm{mm}]$

減衰項による 1 周期当りの散逸エネルギー

[J]

1 周期当りに励振力がな寸仕事 [J]

角柱の $\mathrm{z}$ 方向(crossflow)の変位 $[\mathrm{mm}]$

固定支持した角柱の迎え角 [deg.]

対数減衰率

固定系の值

下流平板がない $(s / d=\infty)$ 場合, あるいは $l_{d} / d=\infty$ (平板長さが測定部全高の場合)の値 時間平均值 
これらの研究から, 後流物体の 3 次元的な干渉効果により柱状物体の振動制御が可能であることが示された. 上述の十字交差系の風洞実験では，下流の円柱，平板は十分長く測定部全高にわたっているが，実用的な観点か らは，後流物体はより短く小さい形状であることが求められる. 本研究では，この後流物体を振動制御に利用す る技術の開発を目的として, 幅 $w=d$ で平板長さ $l_{d}$ が異なる短い下流平板の角柱の crossflow 振動に対寸る干渉効 果を明らかにする。

\section{2. 実験装置, 条件}

図 1 に本研究で用いた風洞測定部の概略と座標系を示寸.測定部断面は $\square 320 \mathrm{~mm}$ である. 図 1 では上下の壁は 省略されている．角柱 $(d=26 \mathrm{~mm}$ ，長さ $L=315 \mathrm{~mm})$ を， crossflow 振動するように風洞側壁の穴を通して外側で 2 枚 板ばねにより水平に弾性支持した，風洞側壁の穴を通る流れの影響を取り除くため角柱にはエンドプレートが取 り付けられている. 幅 $w / d=1$ で厚さ $5 \mathrm{~mm}$ の平板を， $\mathrm{L}$ 字型のサポートによって固定支持した. 前報 ${ }^{(11)} の$ 実験では 平板は測定部全高にわたって張られており本報ではこれを $l_{d} / d=\infty$ とする. 隙間比 $s / d$ は風洞下部のトラバース装 置により設定した.

主流流速 Uは, リング流速計 ${ }^{(12)}$ を用いて計測した．後流速度変動 $u$ を測定する I 型熱線プローブは縦渦を最も 検出しやすい $x / d=1.5, y / d=1.25, z / d=0.4$ の位置に設置した。速度変動と同時に角柱の変位 $Z$ をレーザー変位計に より測定した．変位計は角柱の左右端にそれぞれ設置されており振動モード(並進，回転)も記録した．また，固 定系で角柱に作用寸る変動揚力 $F_{L}$ をロードセルにより測定した. 対数減衰率 $\delta$ と固有振動数 $f_{n}$ は $U=0$ における自 由減衰振動より算出した．表 1 に実験条件を示す．角柱の振動数 $f_{z}$ は全ての条件において $s / d, U$ によらず常に $f_{n}$ に等しいことを確認した．また，平板サポートのみ( $w / d=l_{d} / d=0.38$ に相当)では, KVIV とギャロッピングに対し て影響を及ぼさないことをあらかじめ確認した。

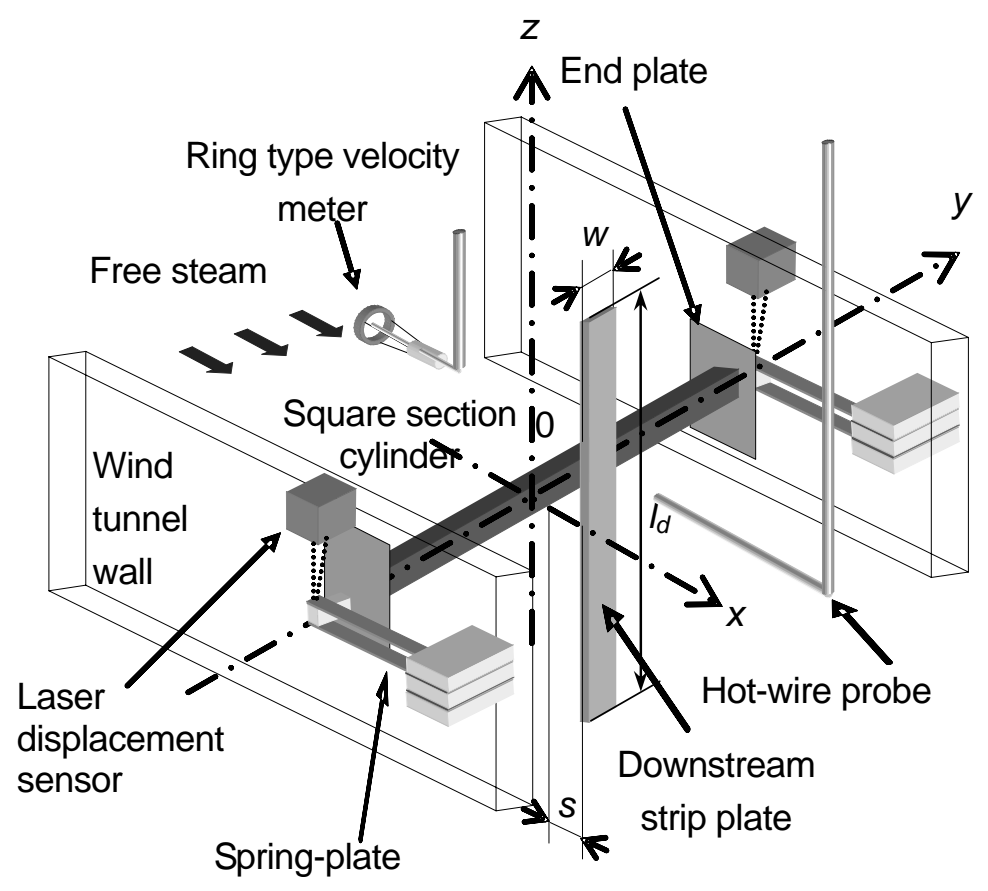

Fig. 1 Arrangement of the experimental apparatus and coordinate system 
Table 1 Experimental conditions

\begin{tabular}{|c|c|c|c|c|c|c|}
\hline & Fig. 2 & Fig.3, Fig.4 & Fig.5(1st, 2nd) & Fig.6 & Fig.8 & Fig.9 \\
\hline$d[\mathrm{~mm}]$ & 26 & 26 & 26 & 26 & 26 & 26 \\
\hline$l_{d} / d$ & $\begin{array}{c}2,4,6,10, \\
\infty\end{array}$ & $\begin{array}{c}1,2,3,4,6 \\
10, \infty\end{array}$ & 2 & 2 & $1.5,2$ & $\begin{array}{c}1,1.25,1.5,1.75,2 \\
3,4,6\end{array}$ \\
\hline$m_{e}[\mathrm{~kg}]$ & 0.15 & 0.15 & 0.15 & 0.15 & 0.15 & 0.15 \\
\hline$k[\mathrm{~N} / \mathrm{m}]$ & 1616 & 1616 & 1616,1618 & - & 1667 & 1667 \\
\hline$\delta$ & 0.03 & 0.03 & 0.03 & - & 0.03 & 0.03 \\
\hline$f_{n}[\mathrm{~Hz}]$ & 16.32 & 16.32 & $16.32,16.37$ & - & $\begin{array}{c}16.03 \\
\sim 16.93\end{array}$ & $\begin{array}{c}16.03 \\
\sim 16.93\end{array}$ \\
\hline$U[\mathrm{~m} / \mathrm{s}]$ & 3.6 & 7.8 & $1.8 \sim 16,2.3 \sim 8.4$ & 7.8 & $2.5 \sim 16.5$ & 8.95 \\
\hline
\end{tabular}

\section{3. 実験結果}

\section{$3 \cdot 1$ 隙間 $s$ と角柱の振動の関係に対する平板長さの影響}

\section{$3 \cdot 1 \cdot 1$ カルマン渦励振に対する短い下流平板の影響}

角柱の $\operatorname{KVIV}(U=3.6 \mathrm{~m} / \mathrm{s})$ において $s / d=6.0$ の下流から平板を近づけた場合の結果を図 2 に示寸.この図において 角柱の振幅 $Z_{r m s}$ と角柱後流の速度変動周波数 $f_{u}$ は, それぞれ単独角柱の振幅 $Z_{r m s}$ と固有振動数 $f_{n}$ で無次元化され ている.

全ての平板について, ®領域( $(s / d>4.0)$ では下流平板の影響は小さ $<, f_{u}=f_{n}\left(=\mathrm{KV}\right.$ の流出周波数 $\left.f_{v}\right), Z_{r m s} \fallingdotseq Z_{r m s \infty}$ と なる KVIV が維持される. さらに平板を近づけると, B領域(4>s/d $>2.5 \sim 1.5)$ では $f_{u}$ が連続的に滑らかに減少し, こ れに伴って $Z_{r m s}$ も減少寸る. $f_{u}$ の減少の程度は $l_{d} / d$ が小さいほど小さい. B領域より小さい $s / d て ゙ は, ~ f_{u}$ と $Z_{r m s}$ の 変化は $l_{d} / d$ にって異なる.

$l_{d} / d=10,6$ の平板では， $l_{d} / d=\infty$ の平板と同様に，領域(2.5 1.7>s/d $\left.>0.4\right)$ で $f_{u}$ は前報で得られた TV の流出周波 数 $f_{v}$ となり, 四領域 $(s / d<0.4)$ では周期的な速度変動は観察されない. 振動については, $l_{d} / d=10$ では $Z_{r m s}$ は D E領 域で十分に抑制されるのに対し, $l_{d} / d=6$ の場合, D領域 $(2.5>S / d>0.6)$ で再び増加し, $l_{d} / d=\infty の$ 場合よりも大きくな る.この振動は, $s / d \fallingdotseq 1.4$ で最大となり，単独角柱の 1.4 倍程度の大きさに達したのち再び減少し，国領域では $Z_{r m s} / Z_{r m s \infty}<0.2$ となり振動が十分に抑制される.

$l_{d} / d=4,2$ の場合, $l_{d} / d=\infty, 6$ とは異なり C領域 $(s / d<1.7)$ では $f_{u}=f_{n}$ で $₫$ 領域の KVIV と同様の速度変動が見られ る. 一方, $Z_{r m s}$ の挙動は $l_{d} / d=6$ の平板とほぼ同様の傾向を示す. $l_{d} / d=4$ では, $\mathbb{C}$ 領域で振動が大きくなり, さらに 平板を近づけると振幅は減少し, $s / d<0.8$ で振動が十分に抑制される. $l_{d} / d=2$ の平板では, $l_{d} / d=4$ と比較すると抑 制領域が小さくなり，また，大きな振動の発生する $s / d$ の範囲は小さい方へずれる. そして $s / d<0.8$ のとき，より 長い平板とは大きく異なり，KVIV は，最大でも単独角柱の $30 \%$ 程度までしか抑制されず，反対に， s/d $\fallingdotseq 0.3$ 付 近で単独角柱の場合より大きな振動が発生した.

これらの結果から, $l_{d} / d \leqq 6$ の平板で $2>s / d>1$ で発生する振動は, 円柱/平板系で見られた”Enhanced Karman Vortex Induced Vibration (EKVIV) ”と類似の現象と考えられる. KVIV に対する下流平板の振動抑制効果は, 平板長さが 短くなるほど小さくなり， $I_{d} / d<2$ の平板では十分な抑制効果が得られないことが示された.

\section{$3 \cdot 1 \cdot 2$ ギャロッピングと縱渦励振に対する短い下流平板の影響}

図 3 にギャロッピングが発生している流速 $(U=7.8 \mathrm{~m} /)$ において $s / d=6.0$ の下流から平板を近づけた場合の実験結 果を示寸，下流平板の $f_{u}$ に対する影響は，KVIV の場合(図 2)とほぼ同様である，すなわち，凡領域(s/d>4.0)では 下流平板の影響は小さく, $l_{d} / d$ によらず $f_{u}=f_{v}(\mathrm{KV})$ が維持される. B領域では下流平板の接近により $\mathrm{KV}$ の渦流出 周波数 $f_{v}$ は滑らかに減少し, その程度は $l_{d} d d$ が小さい方が緩やかである. これより小さい $s / d て ゙ は f_{u}$ は平板長さに より異なり， $l_{d} / d=10 \sim 6$ の平板では領域で $f_{u}$ が Trailing 渦の流出周波数となり, $f_{u}=f_{n}$ となる渦流出が同期する領 域が現われる. 一方, $l_{d} / d=4 \sim 1$ の平板では四領域でカルマン渦の流出が確認される. 
$f_{u}$ に対する影響とは対照的に，制振効果は $l_{d} / d$ により大きく異なる． $l_{d} / d=10$ では $l_{d} / d=\infty$ とほぼ同様に, $s / d \fallingdotseq 6$ で振幅が減少し始め， $s / d \leqq 5.0$ で振動は十分に抑制される。ここで注目寸べき点は，この制振効果が $f_{u}$ には影響 が見られない@領域で現われること，および，この効果の開始から振動が十分に抑制されるまでの s/d の幅が小 さく，下流平板の接近により「突然に」振動が停止することである.この制振効果の現われる $s / d$ は平板が短くな るにつれ小さくなるが，正方形平板である $l_{d} / d=1$ でも $2.0>s / d>1.0$ で十分な抑制効果が得られる.

Trailing 渦による縦渦励振(TVIV)は $l_{d} / d=10$ では $l_{d} / d=\infty$ の場合とほぼ同じ $s / d$ の領域で発生するが, $l_{d} / d=6$ では振 幅が小さくなり，その発生の確認ができる程度となる．そして $l_{d} / d=4$ より短い平板では, 前述のように Trailing 渦に相当する速度変動が確認できず, 図 3 において TVIV の発生は見られない.

$s / d<1.0$ で, $l_{d} / d=2$ では単独角柱の 3 倍, $l_{d} / d=1$ では 1.8 倍近い振動が発生寸る. この振動は, これまでの長い平 板では見られなかった新しい振動である. 図 3 の測定と同時に得られた $l_{d} / d=2,1$ の速度変動スペクトル $S_{u}$ を図 4 に示寸.この図において, $s / d \geqq 1.0$ では $f_{u} \fallingdotseq f_{v}\left(\gg f_{n}\right)$ に相当するピークが確認される. $s / d<1.0$ では, $l_{d} / d=1$ の場合, $s / d \geqq 1.0$ と同様に $f_{n}$ にはピークがなく, 固定系の $f_{v}$ に相当すると思われる周波数にピークが見られる. 一方, $l_{d} d d=2$ では固定系の $f_{v}$ と $f_{u} \fallingdotseq f_{n}$ に相当するピークが確認される. 図 4 の結果は, $l_{d} / d=1,2$ の短い平板を角柱の後流に近 接して置いたときに発生する図 3 の国領域に見られる振動は, 渦励振ではないことを示している. 本論文では, 以下，この振動を後流物体干渉振動(WBIV: Wake Body Interference Vibration) と呼ぶ. この WBIVについては $3 \cdot 2$ 節で検討する.

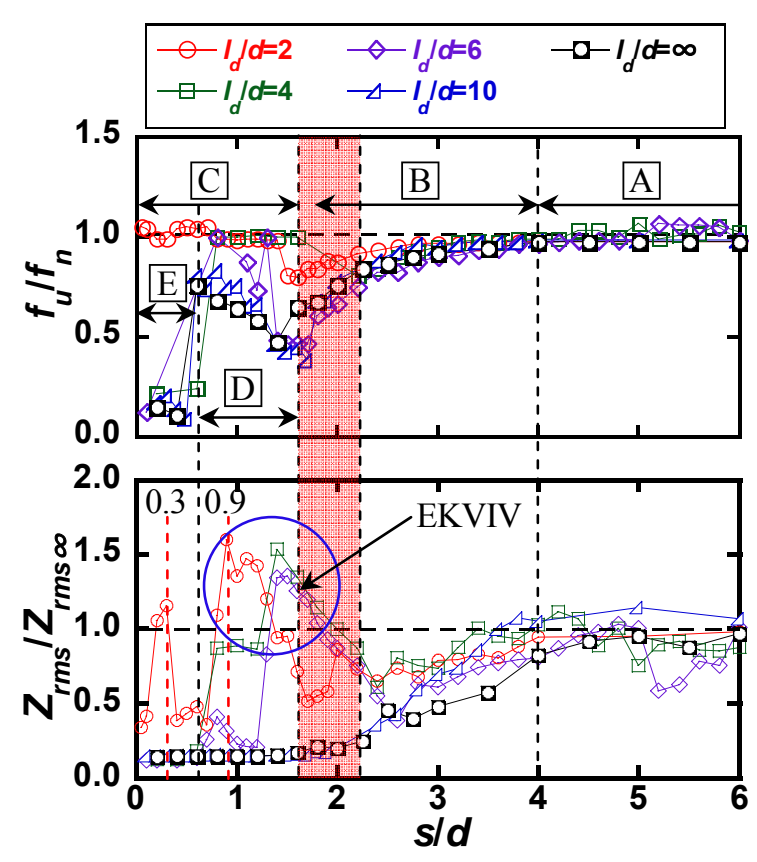

Fig. 2 Influence of the downstream plate length $l_{d}$ on $\operatorname{KVIV}(U=3.6 \mathrm{~m} / \mathrm{s})$

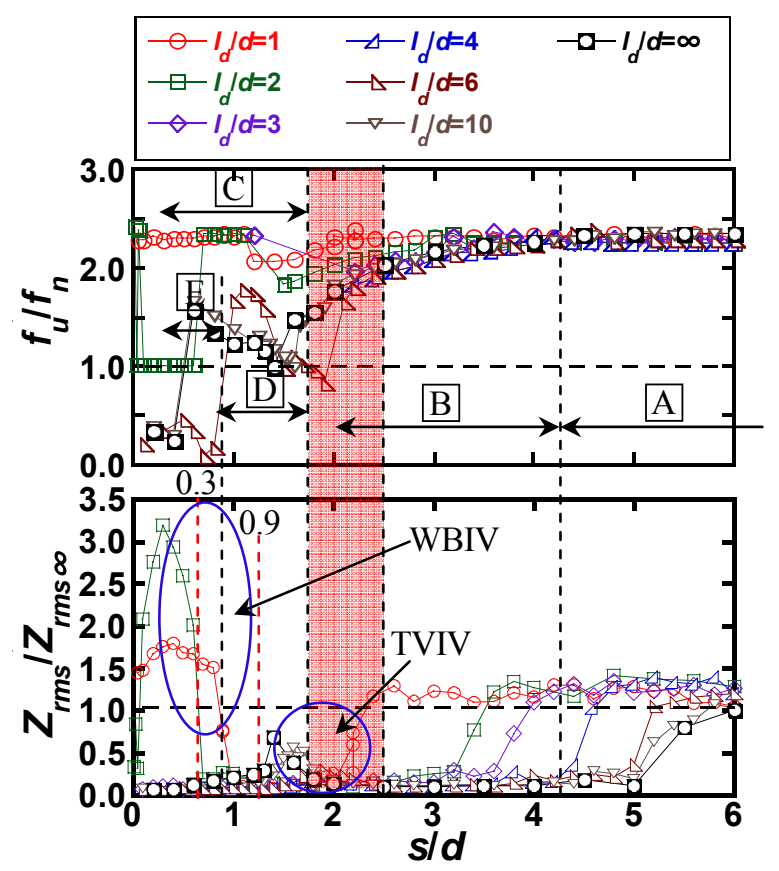

Fig. 3 Influence of the downstream plate length $l_{d}$ on galloping $(U=7.8 \mathrm{~m} / \mathrm{s})$ 

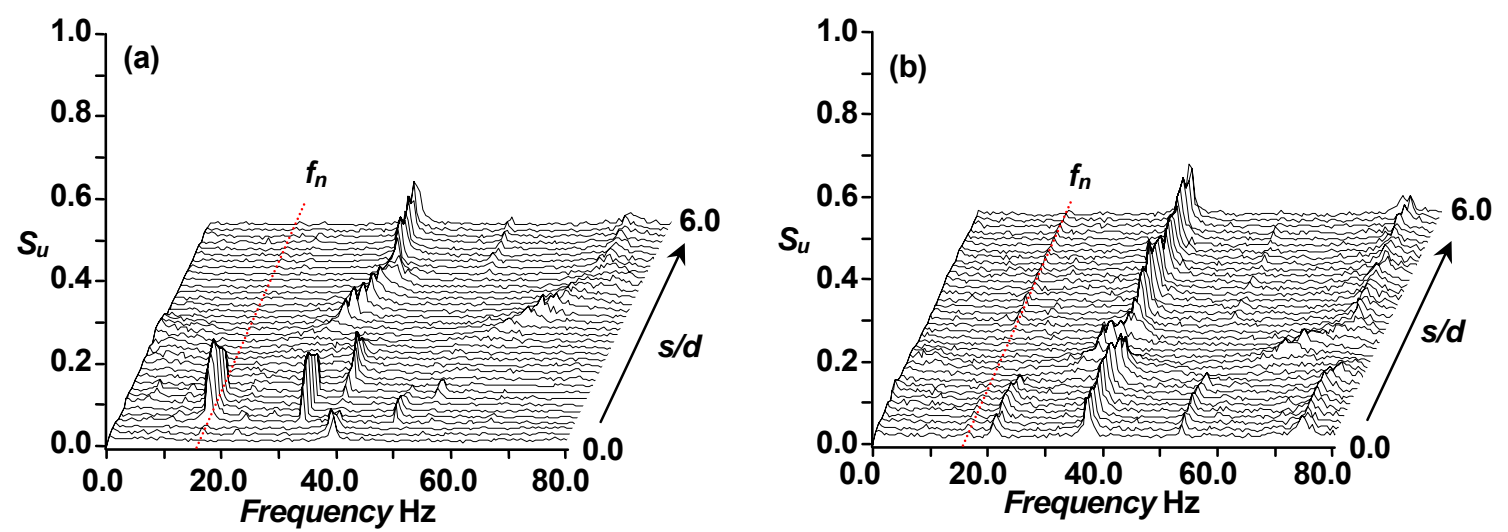

Fig. 4 Influence of downstream strip plate on $S_{u}$ (a) $l_{d} / d=2$, (b) $l_{d} / d=1 \quad(U=7.8 \mathrm{~m} / \mathrm{s})$

\section{$3 \cdot 2$ 短い平板により誘起される振動 (WBIV)の検討}

\section{$3 \cdot 2 \cdot 1$ 流速に対する振動挙動}

以上のように, 短い平板 $\left(l_{d} / d=2\right)$ を後流に設置した場合の振動に対する影響は $s / d$ にり大きく異なる. そこで, $l_{d} d d=2$ の平板を, KVIV 流速で大きな振動(EKVIV)が発生した $s / d=0.9$ (図 2)と, ギャロッピング流速で WBIV が最 大となる $s / d=0.3$ (図 3), 十分なギャロッピング抑制効果が現われる $s / d=2.0$ に設置し, 流速 $U$ を変化させ速度変動 $u$ と角柱の変位 $Z$ を測定した. これらの実験中, $s / d=0.3$ と $s / d=0.9$ については 2 回ずつ測定を行った. 結果を, 図 5 に単独角柱の結果と併せて示寸.

$s / d=0.9$ では単独角柱と同様に $3.4 \leqq U \leqq 4.0 \mathrm{~m} / \mathrm{s} \sim 4.4 \mathrm{~m} / \mathrm{s}$ の範囲で $f_{u}\left(=f_{v}: \mathrm{KV}\right)=f_{n}$ となり KVIV が発生するが，その 流速範囲, 最大值ともに単独角柱の場合よりかなり大きい. これ以上の流速では, 1 回目と 2 回目で振幅の大き さは異なるが，U>5.3m/s 6.0 m/s で振動が再発生する. この振動は流速の増加に伴い急激に増加したのち減少し, $U>9.0 \mathrm{~m} / \mathrm{s}$ でほぼ一定となる。 $f_{u}$ は振幅が大きい領域では $f_{u}=f_{n}$ となり，U>9.0m/s の振幅が小さい領域では, $f_{u}$ は 固定系からのカルマン渦流出周波数 $f_{v 0}$ とほぼ等しくなる. したがって，U>5.3m/s $\sim 6.0 \mathrm{~m} / \mathrm{s}$ の振動において $f_{u}$ と $f_{v 0}$ の相違が大きいことから KVIV と考えにくく，このような高速流の限られた範囲での振動再発生の原因は不明で ある.

$s / d=0.3$ では, $3.4 \leqq U \leqq 4.0 \mathrm{~m} / \mathrm{s}$ で $f_{u}=f_{n}$ となりこの範囲の $Z_{r m s}$ と $U$ の関係も単独角柱と同様であることから図 2 の $l_{d} / d=2, s / d=0.3$ に見られる大きな振動は KVIV と判断される.これを除く $U \leqq 5.0 \mathrm{~m} / \mathrm{s}$ では，振幅は小さく $f_{u}$ は $f_{v 0}$ に等しい. $U>5.0 \mathrm{~m} / \mathrm{s} \sim 5.6 \mathrm{~m} / \mathrm{s}$ で, $U$ に対して発散的に増加する振動が発生する. この振幅が大きい範囲では $f_{u}=f_{n}$ となる．また，振動の発生する下限流速は単独角柱のギャロッピングよりも低い.

$s / d=2.0$ では $3.4 \leqq U \leqq 4.2 \mathrm{~m} / \mathrm{s}$ で KVIV が発生するが，他の 2 つの $s / d$ と比べて振幅は小さい. $4.2<U<10.3 \mathrm{~m} / \mathrm{s}$ で は振動は発生せず, $U>4.2 \mathrm{~m} / \mathrm{s}$ で $f_{u}$ は $f_{v 0}$ よりもやや小さい值となる. U>10.3 $\mathrm{m} / \mathrm{s}$ では振幅が徐々に増加し, $14.9<U<15.6 \mathrm{~m} / \mathrm{s}$ では $s / d=0.9$ とほぼ同様の值に達する．これ以上の流速で振幅は再び減少する. この結果から， $l_{d} / d=2 ， S / d=2.0$ のとき KVIV とギャロッピングがともに抑制されることが確認される.

これらの結果から,$l_{d} / d=2$ の平板によって KVIV 流速の $s / d=0.9$ で発生した大きな振動は KVIV が強化された振 動(EKVIV)であることが確認される. これに対して, ギャロッピング流速での $s / d=0.3$ 発生した大きな振動(WBIV) は流力弾性振動(Fluid Elastic Vibration: FEV)的な挙動を示寸が, この段階では渦励振かギャロッピングであるかの 判断は困難である. 


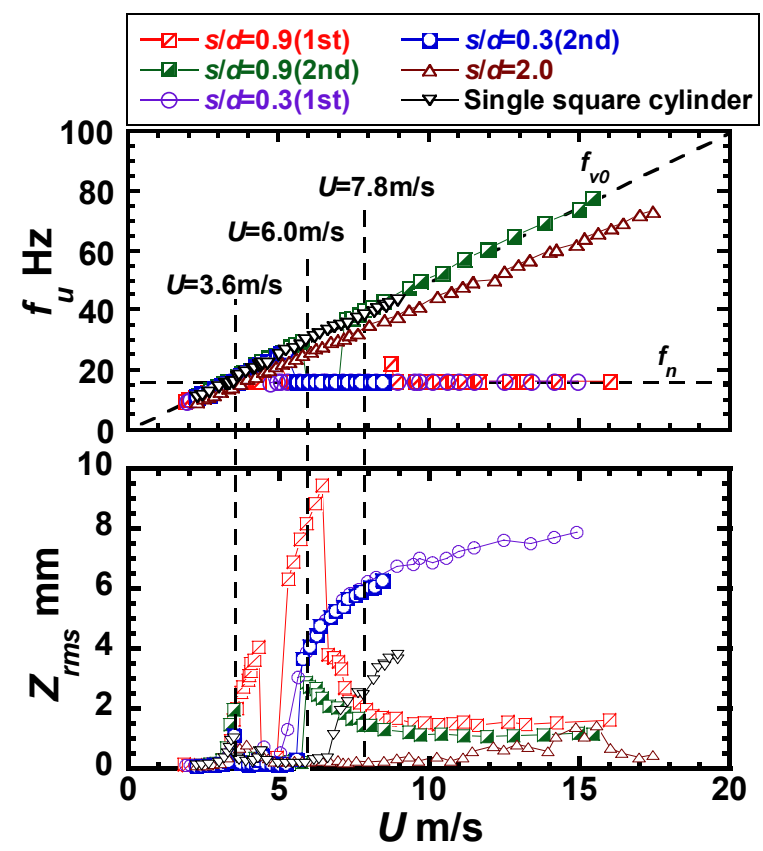

Fig. 5 Variation of $Z_{r m s}$ and $f_{u}$ with $U$ at $s / d=0.3,0.9$ and 2.0 for the plate $l_{d} / d=2$

\section{$3 \cdot 2 \cdot 2$ 固定角柱に作用する変動揚力}

図 3 の $l_{d} / d=2, s / d=0.3$ で発生した WBIV が渦励振であるか否かを調べるため, 角柱を固定した場合にこれに作 用する揚力 $F_{L}$ と速度変動 $u$ を測定した. 流速 $U=7.8 \mathrm{~m} / \mathrm{s}$ として $l_{d} / d=2$ の平板を $s / d=6.0$ の下流から近づけた場合の $u$ と $F_{L}$ のリニアスペクトル $S_{u}$ と $S_{L}$ を図 6 に示す.

図 6(a)において，s/dによらず $S_{u}$ にはある周波数 $f_{u}$ における明瞭なピークと $2 f_{u}$ におけるより鈍いピークが見ら れる. 一方, 図 6(b)の揚力のスペクトル $S_{L}$ は, 上述の $f_{u}$ と等しい周波数 $f_{L}$ でより明瞭な単一のピークを持つ. こ れら $f_{u}, f_{L}$ のストローハル数 $S t_{u}, S t_{L}$ は, $s / d>2.7$ ，および $s / d<1.6$ において固定角柱からのカルマン渦流出周波数 の $S_{0}=0.13$ にほぼ等しいことから, 図 2, 図 3 の曰回四領域の $f_{u}$ がカルマン渦によるものであることが再確認さ れる. 一方, 図 3, 図 4 の国領域の $f_{n}$ に相当するピークは観察されない。 この結果から, 弾性支持角柱の場合の 図 4(a)で $0.1<s / d<0.6$ において見られる $f_{n}$ での鋭いピークは渦流出によるものではなく角柱の振動によるものであ ると考えられる. そして, 図 3 の $s / d<1.0$ の領域で発生した振動は, 渦流出によるものではなく流力弾性振動であ る可能性が示された.
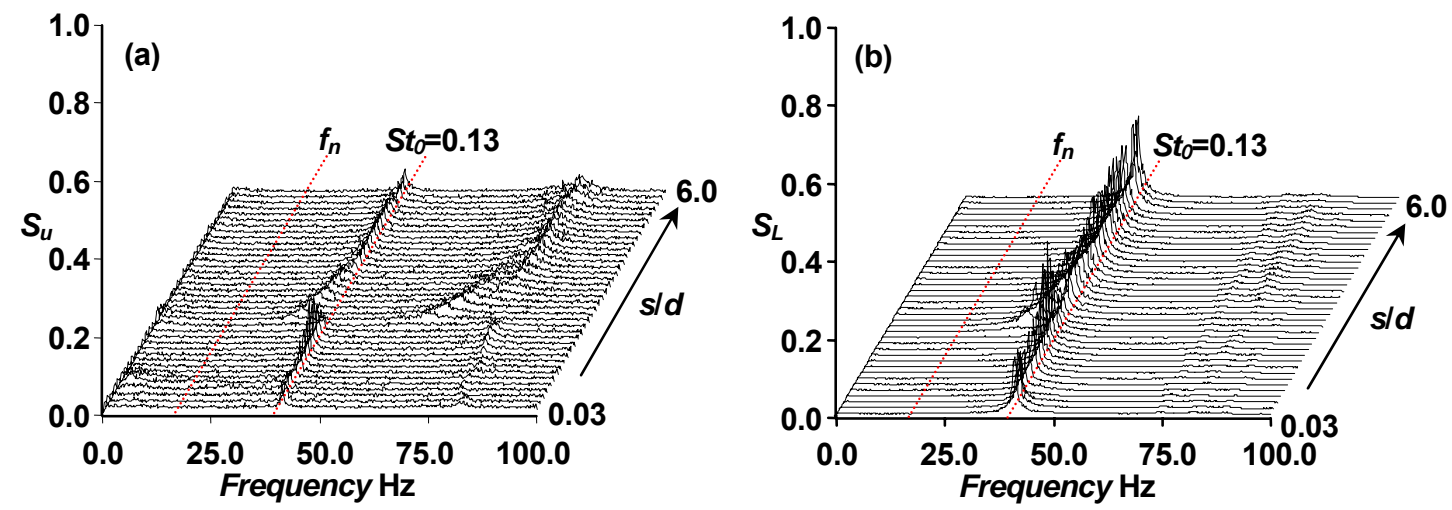

Fig. 6 Spectra of $u$ and $F_{L}$ for fixed system with $l_{d} / d=2$ strip plate $(U=7.8 \mathrm{~m} / \mathrm{s})$ : (a) $S_{u}$ and (b) $S_{L}$ 


\section{3・3 WBIV の流力弾性振動の可能性の検証}

\section{$3 \cdot 3 \cdot 1$ 角柱と平板の相対的位置の効果について}

流力弾性振動の本質は，変位あるいは振動に対する不安定性にある.したがって，3・2 節で示された WBIV は 角柱と短い下流平板の相対的位置の変化が変位方向の流体力を発生させて不安定性の原因となっている可能性が ある。そこで，図 7 のように平板を隙間 $s$ に相当する長さのブラケットを用いて角柱に固定した T型フィンがギ ヤロッピングに与える影響を調べた。平板とブラケットは幅 $w=d$ で厚さ $5 \mathrm{~mm}$ のバルサ材製である. 平板には， 振動の抑制とWBIV の誘起が顕著に見られた $l_{d} / d=2$ と $l_{d} / d=1.5$ の 2 枚を用いた. ブラケット長さを $s / d=0.2 \sim 6.0$ とし，速度変動 $u$ と角柱の変位 $Z$ を測定した。流速はギャロッピングが発生する $U=8.95 \mathrm{~m} / \mathrm{s}$ で一定とした。あら かじめ行ったブラケットのみを角柱に取り付けて流速を変化させた実験により，ブラケットは，角柱の振動と渦 流出にほとんど影響がないことを確認した。

困 8 に $Z_{r m s}$ と $s / d$ の関係を角柱/平板の結果(図中の”D-plate”)と併せて示す. $l_{d} / d=1.5$ の $\mathrm{T}$ 型フィンの場合，1.4 $\leqq s / d \leqq 2.0$ でギャロッピングが抑制され， $s / d<1.4$ で大きな振動(WBIV)が発生する.これは，角柱/平板系とほぼ同 じ $s / d$ の範囲で起こることが分かる．ただし， $\mathrm{T}$ 型フィンによる $s / d<1.4$ の振動振幅は，対応する角柱/平板の場合 の 1.5 倍程度となる. $l_{d} / d=2$ の $\mathrm{T}$ 型フィンの場合, ギャロッピングの抑制効果は角柱/平板系と同じであるが, $s / d<1.4$ では振動が発生しなかった。

この結果をもとに，ブラケット長さ $s / d=0.3$, 流速 $U=8.94 \mathrm{~m} / \mathrm{s}$ として, 平板長さを $l_{d} / d=1 \sim 6$ で変化させ，角柱 の変位 $Z$ を測定した．結果を角柱/平板系の結果と併せて図 9 に示す.ただし，表 1 のような実験条件の相違を考 慮して，スクルートン数 $S_{c}$ により振幅を正規化した。 この図から，どちらの系においても $l_{d} / d>3$ では振動が発生 せず， $\mathrm{T}$ 型フィンにより角柱/平板系と定性的にほぼ同じギャロッピング抑制効果が得られることが分かる.しか し，平板が短いときに誘起される WBIV については角柱/平板系では $l_{d} / d=2.0$ で振幅が最大となるのに対し， T 型 フィンでは $l_{d} / d=1.5$ で最大振幅が得られた。これらの結果において， T 型フィンでも $s / d<1.4$ で WBIV が誘起され ることから，角柱/平板の相対的位置の変化は，WBIVの誘起に不可欠な要因ではないことが分かる.

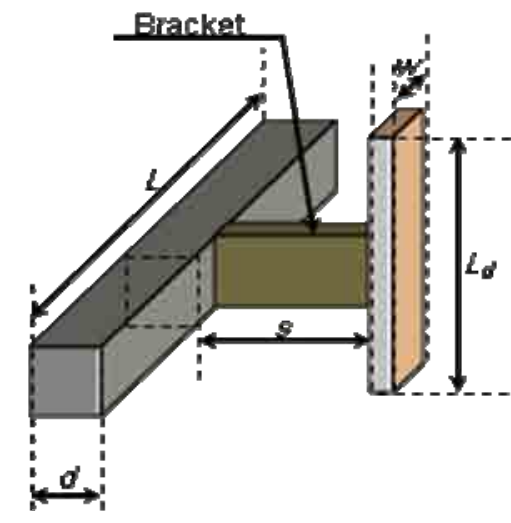

Fig. 7 Arrangement of the T-shape fin

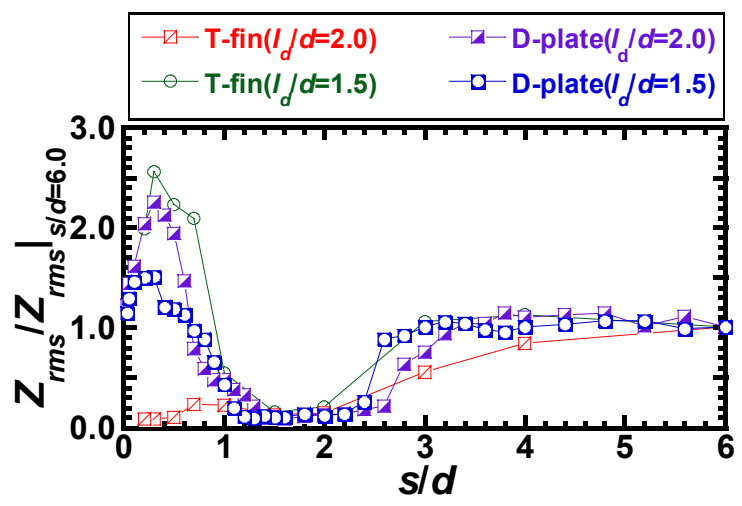

Fig. 8 Interference of the T-shape fin on galloping $(U=8.95 \mathrm{~m} / \mathrm{s})$

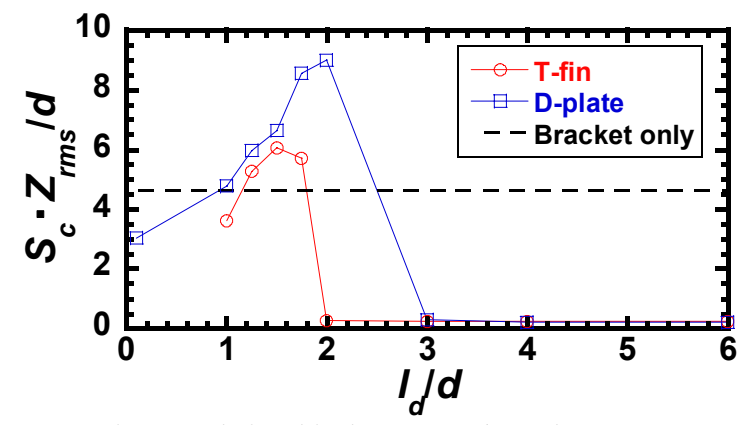

Fig. 9 Relationship between $l_{d} / d$ and WBIV $(\mathrm{s} / \mathrm{d}=0.3, U=8.95 \mathrm{~m} / \mathrm{s})$ 


\section{$3 \cdot 3 \cdot 2$ 短い平板により誘起される振動の予測}

振動物体に作用する流体力を $F_{z}(t)$ 求め振動を予測することは一般に困難である. しかし, 代表的な流力弾性振 動(FEV)であるギャロッピングに対しては, 同じ形の物体が式(1)で与えられる迎え角 $\alpha$ で一様流中に静止している 場合の時間平均の揚力 $\overline{F_{L}}$ と抗力 $\overline{F_{D}}$ の合力である流体力 $\overline{F_{Z}}$ に等しいとする準定常の仮定 ${ }^{(13)}$ に基づく予測法が確 立されている.

$$
\alpha=\tan ^{-1}(-\dot{Z} / U)
$$

$\overline{F_{L}}$ と $\overline{F_{D}}$ は実験的, あるいは数值計算により求められ, その合力 $\overline{F_{z}}$ を振動速度 $\dot{Z}$ の 3 次 7 次の高次多項式 で近似することにより運動方程式から解析的に，あるいは数值計算により $Z_{A}$ が求められる. しかし，一般にはこ の近似は適用できないので，エネルギーに基づく新たな予測法を提案し，WBIV の予測を行う.

角柱が周期 $T$ の振動をしているとき励振力 $F_{Z}$ が 1 周期の間にな寸仕事 $w_{F Z}$ は,

$$
W_{F Z}=\int_{0}^{T} F_{Z} \dot{Z} d t
$$

また，減衰係数 $C_{e}$ の減衰項による散逸エネルギー $w_{c}$ は,

$$
W_{C}=C_{e} \int_{0}^{T} \dot{Z}^{2} d t
$$

角柱が定常的に振動している場合，

$$
w_{F Z}=w_{C}
$$

を満足する振幅 $Z_{A}$ が実現する．振動が，

$$
Z=Z_{A} \sin \left(2 \pi f_{n} t\right)
$$

で表わされるとき，散冕エネルギー $w_{c}$ は式(6)のように $Z_{A}$ の 2 乗に比例する.

$$
w_{C}=2 \pi^{2} C_{e} Z_{A}^{2} f_{n}
$$

次に， $w_{F Z}$ を $Z_{A}$ の関数として表すために，ギャロッピング理論と同様に準定常の仮定を適用して，1 周期中の ある位相 $\theta=2 \pi f_{n} t$ における $\overline{F_{z}}$ を次の手順で求める.

(1) $Z_{A}$ を仮定し，(5)式からある位相 $\theta=2 \pi f_{n} t$ の $Z$ と $\dot{Z}$ を求める.

(2) (1)式より $\alpha$ を求める.

(3) 風洞実験より，(1)，(2)で求めた $Z ， \alpha$ における $\overline{F_{L}}(\alpha)$ と $\overline{F_{D}}(\alpha)$ を測定し，その合力 $\overline{F_{Z}}(\alpha)$ を算出する.

(4) $\theta=0 \sim 2 \pi$ について $\overline{F_{Z}}$ を求め, 式(2)において $F_{Z}=\overline{F_{Z}}$ として $w_{F Z}$ を算出する.

(5) $Z_{A}$ の適当な範囲で(1)〜(4)を行えば, $w_{F Z}\left(Z_{A}\right)$ を得るので，式(4)の条件から $Z_{A}$ を決定する.

実際に，この手順により $w_{F z}\left(Z_{A}\right)$ を求めるには膨大な実験が必要となる。しかし，前節の $\mathrm{T}$ 型フィンの実験から WBIV の Z に対する依存性は低いと考えられるので，これを無視すれば，適当に選んだ $Z_{A} に$ 対して(3)の風洞実験 で求めた流体力を無次元化して得た次式(7)は， $Z_{A}$ によず適用できると考えられる.

$$
\overline{C_{z}}=\overline{C_{L}} \cos \alpha+\overline{C_{D}} \sin \alpha
$$


ここでは, 図 5 の結果を参照して $Z_{A}=7 \mathrm{~mm}$ として風洞実験を行い $\overline{F_{Z}}$ を得た。この $\overline{F_{Z}}$ から(7)式より $\overline{C_{Z}}$ を算出 した結果を図 10 に示す.この図の A の領域では流体力 $\overline{F_{z}}$ が運動方向に作用し，エネルギーを物体に与えている ので，これにより定常的振動が発生していると考えられる.この実験結果を図中の曲線で近似し，上述の方法に より求めた, 流速 $U$ に対する振動振幅 $Z_{A}$ を実験結果と比較して図 11 に示寸.ただし, $Z_{A}=\sqrt{2} Z_{r m s}$ を用いている. $5 \leqq U \leqq 10.7 \mathrm{~m} / \mathrm{s}$ では予測值と実験值がほぼ一致している.これ以上の流速で計算值は, $Z_{A}>\left(l_{d}-d\right) / 2$ となり, これ は角柱が平板外側に渡って振動することを意味している。この場合，Zの影響を無視できないものと考えられ， 計算值の測定結果からのずれが大きくなる. 図 11 に見られる実験結果と予測の一致は, WBIV が流力弾性振動の 一つであることを示しており，これを後流物体干渉流力弾性振動(Wake Body Interference Fluid Elastic Vibration: WBIFEV)と呼ぶことが妥当であることを示している.

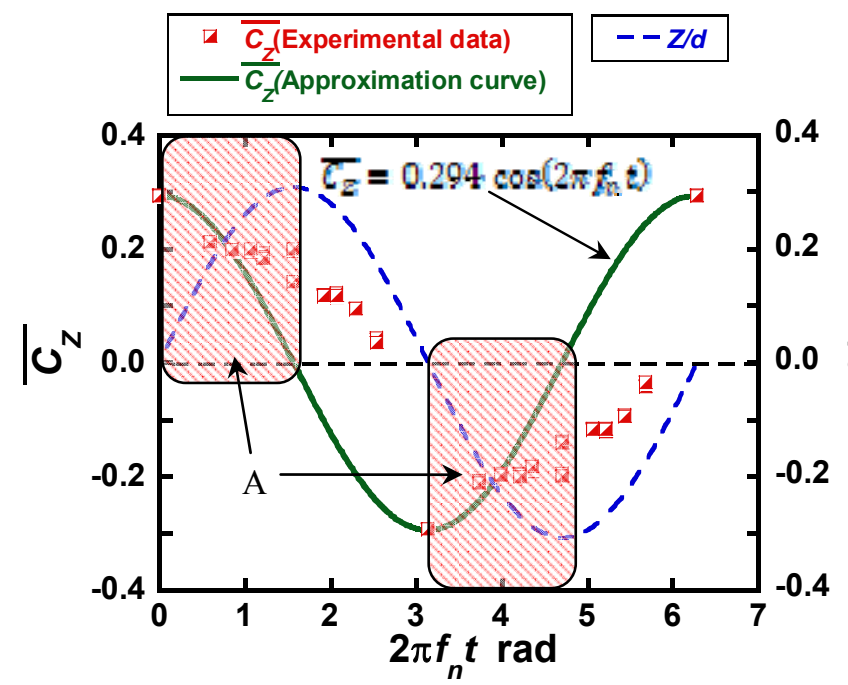

Fig. 10 Fluid force coefficient and displacement vs. $2 \pi f_{n} t$

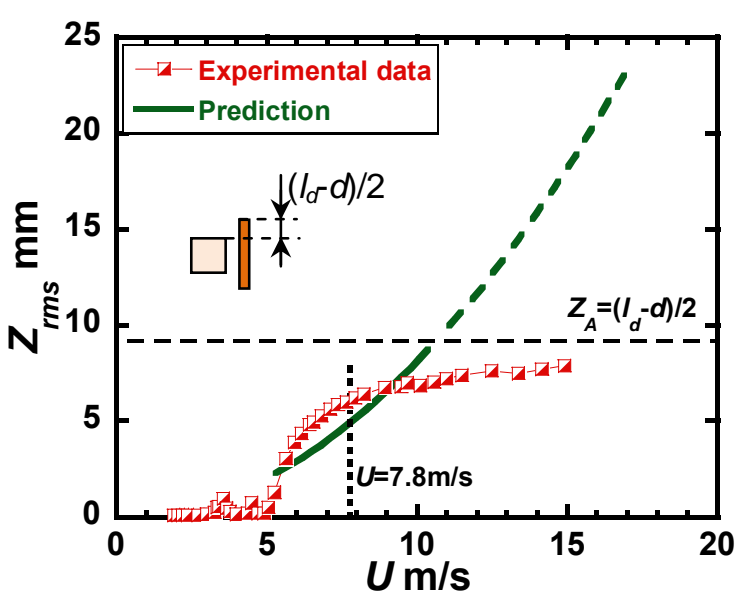

Fig. 11 WBIFEV prediction compared with experiment $\left(l_{d} / d=2, s / d=0.3\right)$

\section{$3 \cdot 4$ 振動に対する平板の影響の $I_{d} / d \sim S / d$ 面上の分類}

以上に述べたカルマン渦励振およびギャロッピングに対する後流平板の影響を, $l_{d} / d \sim s / d$ 面上の領域で表した結

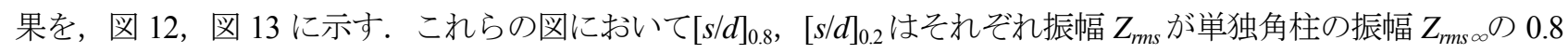
倍, 0.2 倍のときの $s / d$ の值である. $[s / d]_{0.8}$ は平板を下流から近づけたときにカルマン渦励振あるいはギャロッピ ングの抑制が始まる $s / d$ を表し, $[s / d]_{0.2}$ は振動が十分に抑制される $s / d$ の限值とみなされる. EKVIVについては, 単独角柱よりも振動が大きい領域を塗りつぶしで示した. WBIFEV は， $s / d \leqq 1$ で単独角柱の 0.2 倍以上の振動と した.

図 12 に示寸ように，カルマン渦励振の抑制が始まる隙間比 $[s / d]_{0.8}$ は，あまり平板長さの影響を受けず， $l_{d} / d=\infty$ では $[s / d]_{0.8} \doteqdot 3.8$ であるのに対し, $l_{d} / d=2$ では $[s / d]_{0.8} \doteqdot 3$ に減少する程度である.一方, 振動が十分に抑制される $[s / d]_{0.2}$ は, $[s / d]_{0.8}$ に比べ小さい $l_{d} / d$ に対して $s / d$ が減少する傾向が強い. EKVIV は, $s / d<0.8 \sim 2.6, \quad l_{d} / d=2 \sim 6$ の領域で発生 し, 単独角柱よりも振動が大きい領域は $l_{d} / d$ が小さくなるにつれ， $s / d$ の小さな領域に移動する傾向がみられる.

図 13 に見られるように，ギャロッピングの場合も，平板が短くなるにつれて $[\mathrm{s} / \mathrm{d}]_{0.8}$ と $[\mathrm{s} / \mathrm{d}]_{0.2}$ は小さくなるが最 も短い $l_{d} d d=1$ の平板でも十分な抑制効果が得られ, また, $[s / d]_{0.8}$ と $[s / d]_{0.2}$ の差が小さく, 下流平板を僅かに近づけ ると振動が急激に小さくなる.KVIVおよびギャロッピングとは異なった振動が誘起される現象として, $l_{d} / d \geqq 10$, $s / d \fallingdotseq 1 \sim 1.7$ の領域では縦渦励振が， $l_{d} / d<1 \sim 2, s / d<1$ の領域では WBIFEV が発生する. 


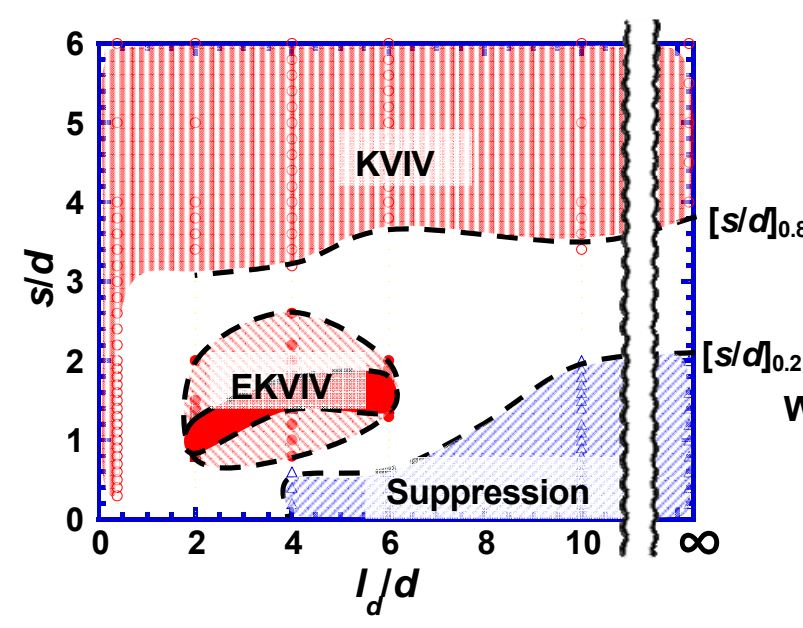

Fig. 12 Vibration map of square cylinder on $l_{d} d d$-s/d plane under KVIV $(w / d=1.0, R e=6200)$

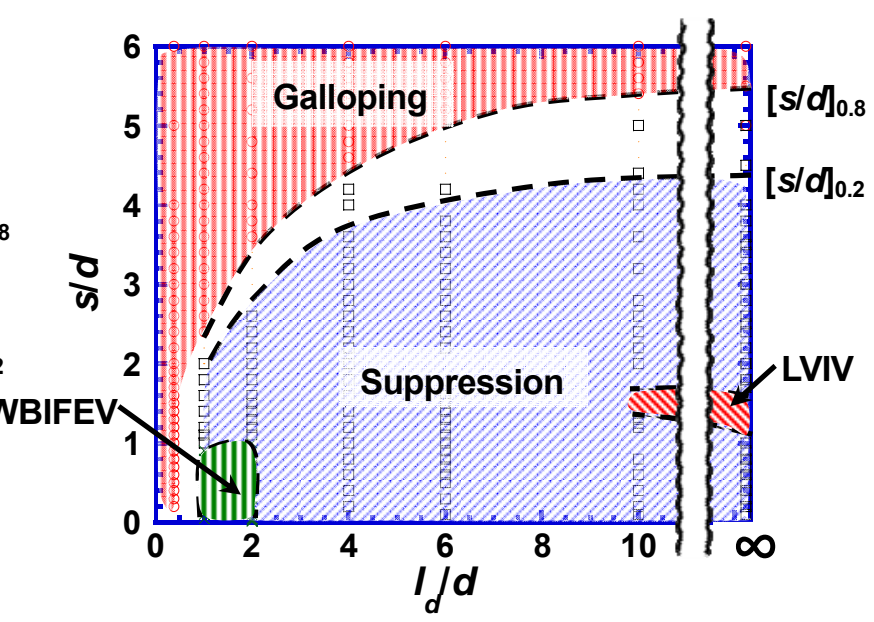

Fig. 13 Vibration map of square cylinder on $l_{d} / d-s / d$ plane under Galloping $(w / d=1.0, R e=13400)$

\section{4. 結言}

前報で見出した，角柱の近接後流に十字交差配置した幅 $w=d$ の無限に長い平板の振動に対する影響を振動制 御に利用寸ることを目的として，平板長さが有限の場合にどのようになるかを風洞実験により調べ，以下の結果 を得た。

(1) 下流平板が短くなると角柱のカルマン渦励振(KVIV)の抑制効果は小さくなり， $l_{d} / d<2$ の平板では十分な抑 制効果が得られない. また $l_{d} / d<6$ の平板では, その干渉により振幅が大きくなる現象(EKVIV)が発生する.

(2) 短い平板でも十分なギャロッピング抑制効果が得られる. 例えば $l_{d} / d=1$ の正方形平板でも $1.0 \leqq s / d \leqq 2.0$ で ギャロッピングは効果的に抑制される.

(3) Trailing 渦による励振(TVIV)は平板が短くなると小さくなり， $l_{d} / d<4$ では発生しない.

(4) $l_{d} d d \leqq 2$ の平板を $s / d \leqq 1.0$ に設置すると, 非常に大きな振動が発生する. この振動は, これまで知られてい ない流力弾性振動と判断されることから，これを「後流物体干渉流力弾性振動（WBIFEV）」と呼ぶこと を提案する.

これらの現象は，角柱のアスペクト比や平板の取り付け位置に大きく影響されることが予想される．また， WBIFEV はギャロッピングとは異なるこれまで知られていなかった振動であり, 流体力学的観点からの興味とと もに, 事故防止, および, 振動の積極的利用の観点から工学的, 工業的に重要であることから, その発生機構, 発生条件とその大きさの予測について今後, 他の研究らによる後流干渉に関する研究の展開が望まれる.

\section{文献}

(1) G.V. Papaioannou, D.K.P. Yue, M.S. Triantafyllou, and G.E. Karniadakis, "On the effect of spacing on the vortex-induced vibrations of two tandem cylinders", Journal of Fluids and Structures, Vol.24, Issue 6 (2008), pp. 833-854.

(2) Sangil Kim, Md. Mahbub Alam, Hiroshi Sakamoto, and Yu Zhou, "Flow-induced vibration of two circular cylinders in tandem arrangement. Part 1: Characteristics of vibration", Journal of Wind Engineering and Industrial Aerodynamics, Vol.97, Issue 5-6 (2009), pp. 304-311.

(3) Sangil Kim, Md. Mahbub Alam, Hiroshi Sakamoto, and Yu Zhou, "Flow-induced vibration of two circular cylinders in tandem arrangement. Part 2: Suppression of vibrations", Journal of Wind Engineering and Industrial Aerodynamics, Vol.97, Issue 5-6 (2009), pp. 312-319. 
(4) I. Korkischko, and J.R. Meneghin, "Experimental investigation of flow-induced vibration on isolated and tandem circular cylinders fitted with strakes", Journal of Fluids and Structures, Vol.26, Issue 4 (2010), pp. 611-625.

(5) B.H.L. Gowda, and R. Ajith Kumar, "Flow-induced oscillations of a square cylinder due to interference effects", Journal of Sound and Vibration, Vol.297, Issues 3-5, (2006), pp. 842-864.

(6) R. Galvao, E. Lee, D. Farrell, F. Hover, M. Triantafyllou, N. Kitney, and P. Beynet, "Flow control in flow-structure interaction", Journal of Fluids and Structures, Vol.24, Issue 8 (2008), pp. 1216-1226.

(7) M. Shirakashi, K. Mizuguchi, and H.M. Bae, "Flow-induced excitation of an elastically-supported cylinder caused by another located downstream in cruciform arrangement”, Journal of Fluids and Structures, Vol.3, Issue 6 (1989), pp. 595-607.

(8) M. Shirakashi, T. Takahashi, I. Kumagai, and T. Matsumoto, "Vortex-induced vibration of the upstream cylinder of a two-cylinder system in cruciform arrangement", Journal of Computational and Applied Mechanics, Vol.2, No.1 (2001), pp.103-122.

（9）小出瑞康，加藤直人，高橋勉，白樫正高, “円柱の下流に十字交差配置された帯状の平板による振動制御：第 2 報,帯 状平板による渦励振の励起と抑制”，日本機械学会論文集 B 編, Vol.75, No.752, (2009), pp. 691-669.

(10) M. Koide, N. Kato, S. Yamada, Y. Kawabata, T. Takahashi, and M. Shirakashi, "Influence of a cruciform arrangement downstream strip plate on crossflow vibration of a square cylinder", Journal of Computational and Applied mechanics, Vol.8, No.2 (2007), pp.135-148.

(11) 川畑佑介, 高橋勉，白樫正高, “角柱のギャロッピングに対する下流平板の影響”, 日本機械学会論文集 B 編, Vol.75, No.754 (2009), pp. 1304-1309.

(12) 小出瑞康，高橋勉，白樫正高，“風洞実験における低流速測定を目的としたリング流速計の試作”，日本機械学会論 文集 B 編, Vol.67, No.657 (2001), pp. 1105-1111.

(13) R.D. Blevins, Flow-Induced Vibration (second edition), (1990), pp.104-120., Van Nostrand reinhold. 